THURSDAY, FEBRUARY II, 1892.

\section{THE VACANT CHAIR OF ASTRONOMY AT} CAMBRIDGE.

$\mathrm{O}$ UR Note of last week has brought us several communications with regard to the Chair of Astronomy rendered vacant by the lamented death of Prof. Adams. Before the note was written only certain names had reached us; but since then we have heard from the Rev. A. Freeman that he is a candidate for the Chair, and he has also been good enough to forward to us copies of papers on astronomical subjects which he has communicated to the Royal Astronomical and the Cambridge Philosophical Societies. We are very glad, therefore, to comply with what we presume is his desire that we should state that he is a candidate.

The other communications to which we refer are of more general interest, as they raise questions almost of national importance. We are informed, for instance, that it has been suggested that the Observatory should be disconnected from the vacant Chair. That is the first point. Another is that there is an idea prevailing at Cambridge that in such a subject as Astronomy the Professorships nay be well regarded as honourable rewards or pensions to men who have rendered the University service as College tutors, or who have spared the professors and tutors labour by acting as coaches, the contributions these gentlemen may have made to astronomical science being considered as a matter of secondary importance.

With regard to the first point, we believe it will be generally conceded-it certainly will be conceded by those who know anything about the organization of that land of Universities, Germany-that an astronomical Observatory must take exactly the same place with regard to astronomy as physical, chemical, and biological laboratories do with regard to the sciences for which their aid is now regarded as essential, even at Cambridge. It should be clear, therefore, that in an University which professes to teach astronorny--to say nothing of that University rendered illustrious by the name of Newton-it would be as impolitic and as stupid a thing to dissociate the physical laboratory from the Professorship of Physics, the chemical laboratory from the Professorship of Chemistry, and the biological laboratories from the Professorships of Biological Science, as it would be to sever the astronomical Observatory-which in a University should always be a laboratory as well-from the subject of astronomy. And we confess it does not seen possible to us that such a step can be seriously contemplated; but certainly, were it done, the University would become a laughingstock; and more than this, Cambridge would be reversing its scientific history. As far back as 1704, the Plumian Professorship of Astronomy was founded for the promotion of practical astronomy, especially to describe the parts and uses of astronomical instruments, and to prove and exemplify the mathematical formulæe required in the reduction of observations. It is worth while to point out that the wisdom of this foundation is proved by the fact: that this is exactly the basis on which the astronomical subjects are generally treated in the German Universities. Take, for instance, the ObservaNo. 1163 . VOL. 45$]$ tory at Leipzig. Prof. Bruns lectures to his students $\mathrm{for}$ four hours a week on the parts and uses of astronomical instruments and the cognate subjects ; and, in addition to these, the mathematical treatment required in the reduc tion of observations and in ordinary computations ate included in a separate course of instruction of two hours a week, and the students of both these courses join in the work of the Observatory, and are glad to do it.

We do not know whether the terms of Dr. Plume's be:quest are still adhered to by the present Plumian Professc $r$ of Astronomy, but there is no doubt that it was in relc. tion to the work so definitely laid down for this Chair th: $t$ the Cambridge Observatory was established; and it is a matter of history that, when Prof. Woodhouse was suc:ceeded in 1828 by Airy as Plumian Professor and Directc $r$ of the then newly-erected Observatory, his work in the direction laid down by the foundation marked an epoch in modern astronomy. There are few first-clasis Observatories in the world at the present time in which the method of publishing adopted by Prof. Airy for the Cambridge Observatory is not followed with faithful accuracy, and let it be mentioned that all of the work, down to the minute computations and even the copyin:r, was done by Airy himself.

During the tenure of the Lowndesian Professorship by Adams, the Observatory was separated from the Plumian Professorship and transferred to the Lowndesian, and this represents the present condition of things.

It is perfectly obvious, from what has been said, that to transfer now the Observatory from both the Professo ships would be to run counter to the past history of Cambridge. It should be equally clear that this among many bad results might, in all probability, follow. The modicum of astronomy in the general sense now tauglt at Cambridge would be taught by men who, by the absence of material means, would not only be incapac tated from teaching the subject properly, but even fror learning the new developments of it. The Professorshi, might soon become an intensified sinecure; while the Director of the Observatory, who would be the only one in the position of being able to learn, would yet, by the conditions of the problem, not be in a position to teach.

We now come to the second point-that relating t, the astronomical qualifications of those who are cand:dates for the Chair. We cannot believe that this preser $t$ year of grace-with a new astronomy breaking in upon us on all sides by the introduction of physical inquiries, exper:mental work, application of new instruments, and the like - can be a good time for dispensing with a practical acquaintance with the subject among the candidates for a Chair of Astronomy at Cambridge or anywhere else.

The subject, indeed, is one in which we are at present scarcely holding our own, while America and Germany are spending hundreds of thousands of pounds for the new equipments necessitated by the new methods. Surel $y$ Cambridge cannot be content that the Professor appointed is to be absolutely ignorant of the material equipment of the science; that he shall have no instruments to demonstrate to his students; nay, that he may not know one en 1 of one from the other, and at the same time be rather proud that it is so, on the ground that contact with masses of metal might probably interfere with the purity of th? conceptions of his mathematical mind. 
It is, of course, agreed by everybody that there are mathematical investigations required in astronomy which can be, and have been, brilliantly carried out without the use of astronomical instruments. Looming large among these are tables such as those produced by Leverrier, Newcomb, Hansen, and many others that might be named; and were there at present among us a man who was distinguishing himself in such investigations, it might, under certain circumstances, be permissible to waste an Observatory by placing him at the head of it. But these are not the present circumstances. As it is, although England and Cambridge have made noble contributors to astronomy in the past, at the present moment there is no such man. The raw material produced by Greenwich is worked up abroad, and reimported for home consumption; while, on the other hand, the number of Observatories and Astronomical Chairs in this country is so small, that there are no inducements to an astronomical career, so that astronomy bids fair to be soon an extinct profession.

This is why we believe that it is essential, to save the situation, that astronomical professorships should be conferred upon astronomers, and that the existing Observatories should be saved from becoming sleepy hollows for mathematicians, however distinguished, who have given no hostages to fortune in the shape of noble astronomical work achieved.

The recent gift to the University by the late Mr. R. S. Newall even suggests that the present time might be taken advantage of to extend the present Observatory-if by no other means, then by a national subscription-so that it may become an institution as important for the promotion of astronomy as the Cavendish Laboratory, and others which might be named, are for the sister sciences.

We believe that there would be a general enthusiasm to contribute towards a building which should be a national memorial to Newton and Adams in the University which they have rendered illustrious by their labours; and if such a consummation could be aided by the suppression or suspension for a time, of one of the existing Chairs, we believe that the Cambridge authorities would have public opinion with them. We do not think that the number of astronomical students is now very great, or that the classes of the Plumian Professor are inordinately large; probably, therefore, no inconvenience would be caused by such a temporary suspension, while the gain to science and to the University would be permanent.

EDITOR.

THE CATALOGUE OF SCIENTIFIC PAPERS. Catalogue of Scientific Papers (1874-83). Compiled by the Royal Society of London. Vol. IX. (Cambridge: University Press, I891.)

THE Royal Society's "Catalogue of Scientific Papers," 1 of which the ninth volume has just appeared, is the outcome of a movement which dates back nearly forty years. At the Glasgow meeting of the British Association which was held in 1855 , a communication from Prof. Henry, of Washington, was read, " containing a proposal for the publication of [a catalogue of] philosophical memoirs scattered throughout the Transactions of Societies in
Europe and America, with the offer of co-operation on the part of the Smithsonian Institute." This proposal was referred to a Committee consisting of Mr. Cayley, Mr. Grant, and Prof. (now Sir Gabriel) Stokes; and their report was presented next year at the Cheltenham meeting of the Association. The scheme set forth in this report was that of a catalogue embracing only the mathematical and physical sciences, but comprising a subject catalogue as well as a catalogue according to the names of authors. There were to be paid editors, "familiar with the several great branches respectively of the sciences to which the catalogue relates," and the work was to include, besides Transactions and Proceedings of Societies, journals, ephemerides, volurnes of observations, and "other collections not coming under any of the preceding heads."

In this form the scheme came before the Royal Society in March 1857, General Sabine having requested, on the part of the British Association, the co-operation of the Society in the undertaking. The scheme, after the usual amount of discussion in Committees and Councils, at length got upon its feet, walking, however, at first, in a wary and tentative manner. It was narrowed to a manuscript catalogue, the question of printing being deferred; it was to be a catalogue of periodical works in the Royal Society's library only (though it may be remarked, by the way, that that library is particularly rich in scientific serial literature); the suggested American co-operation, moreover, was dispensed with, and the work undertaken at the Society's own charge. In one important respect, however, the scheme was. greatly widened, for the idea of confining the Catalogue to the mathematical and physical sciences, which had been put forward in the report to the British Association, was thrown overboard, and it was wisely decided "that all the sciences should be comprehended." The tentative restrictions were, of course, finally relaxed. It was resolved to extend the indexing to works in other libraries not contained in the library of the Royal Society ; and in I 864 , when the question of printing had to be faced, it was decided to offer the Catalogue to Government for publication.

The cost to the Society of compiling the material for the first series of the Catalogue was considerable, and many of the most eminent of the Fellows had spent no small amount of time, not only in superintending the progress of the work at home, but in corresponding with Academies abroad, with the view of making the list of serials to be catalogued as complete as might be. It was therefore with some reason that the lords of the Treasury, in resolving to print the Catalogue at the public expense, stated that they had regard " to the importance of the work, with reference to the promotion of scientific knowledge generally, to the high authority of the source from which it comes, and to the labour gratuitously given by members of the Royal Society for its production." The printing of this first series of the Catalogue covering the scientific serials from the year 1800 to 1863 , was commenced by the Stationery Office in 1866 , seven Fellows of the Royal Society undertaking to read the proof-sheets gratuitously. The sixth and last volume of the series, completing the alphabet, was issued in 1872 .

It is in the nature of such an undertaking that it never

NO. I I 63 , VOL. 45$]$ 